\title{
EL "CENTRO DE MEDITACIÓN" EN CUERNAVACA, MORELOS, DE AGUSTIN HERNÁNDEZ
}

\section{Beatriz de LA Fuente}

Una de las corrientes de la filosofía contemporánea del arte, desconoce la validez de las teorías que se ocupan de una actividad artística espe. cífica. Dicho de otro modo, no hay una "estética de la arquitectura" distinta a la de la poesía, la escultura o la pintura, Adolfo Venturi en Sul Metodo della storia dell'architettura, ha sido el más efectivo en desacreditar el concepto de que la arquitectura es una manifestación artística única.

La reducción de varias actividades creativas a una sola categoría de arte, ha contribuido a liberar la crítica de la arquitectura de interpretaciones eclécticas que, en cierta medida, la sofocaron durante siglos. De Vitruvio a Serlio, de Vignola a Viollet le Duc, se había puesto énfasis en valorar la arquitectura dentro de una esfera diferente de la de otras expresiones de arte. Se aceptaba, tácitamente, que se trataba de un arte que requería técnicas especiales y conocimientos particulares. Ya que era desigual, debía someterse a reglas teóricas privativas, variables según el gusto y el estilo de la época. De allí el acento en criterios utilitarios, técnicos, funcionales o puramente formales.

Sin embargo, en tiempos remotos, en Egipto, en Grecia, en Mesoamérica y durante la Edad Media, civilizaciones consolidadas por vigoroso espíritu religioso, se expresaban por medio de templos, pirámides y catedrales que se edificaban como unidades armónicas perfectamente integradas. Los ofncios se aprendian bajo la tutela del maestro, y como no se tenía la idea del arte, no había jerarquías entre artes diferentes. Con ojos contemporáneos miramos esos monumentos antiguos y procuramos comprenderlos en su programa original. Cualquier teoría de la arqui. tectura sólo nos permitiría un acercamiento parcial.

Bajo la luz de lo antes dicho se hace inteligible el "Centro de Meditación" de Agustín Hernández, no es tan sólo un edificio, aunque: algunos teóricos formalistas podrían referirse a él como "arquitectura con valores escultóricos". Se trata de una obra indivisible que incorpora elementos de distinto orden: edilicios, escultóricos, pictóricos, simbólicos, y otros más.

Ahora bien; la obra es única, no se iguala con otras realizadas por Agustín Hernández, pero es consecuente con ideas rectoras y esenciales: 
de su quehacer. Hernández ha usado formas geométricas: el cuadro, el círculo, la espiral, que dan fundamento armónico a sus trabajos. $\mathrm{Ha}$ encontrado en los materiales: madera, piedra, barro, vidrio, medios de adecuación con la naturaleza. Ha propuesto que los espacios interiores respondan a los valores humanos del destino de la obra. Ha renovado el significado de monumentos ancestrales al incorporar, actualizándolas, partes de ellos, y ha hecho efectiva la participación de unidades adecuadas a la comunidad.

"El Centro de Meditación" es todo lo anterior, y algo más. El acento en el símbolo llevado a la forma, al espacio, al movimiento, al color, lo distingue de obras anteriores y le otorga unicidad.

En efecto, la concepción de la obra radica en símbolos metafísicos que responden a la particularidad de un programa: la creación de un lugar de reposo para el cuerpo y para el espíritu, y de un sitio que propicia la comunicación del hombre con la divinidad.

Me aproximaré, en lo general, a esos símbolos mixándolos primero en el exterior, y procederé después a apreciarlos en el interior.

La obra, situada en un amplio terreno arbolado, da orden con sus volúmenes y espacios geométricos a la naturaleza que la circunda. Su forma general -reminiscencia prehispánica- es la figura de una enorme cabeza de serpiente con sus fauces abiertas. Sus vistas exteriores se organizan de modo tal, que crean una sucesión ininterrumpida de huecos y superficies de diversas texturas.

Lo que distingue principalmente a las superficies en su continuidad de mosaico de ladrillo blanco, es el paño constituido por hiladas de rectángulos de un lado, en tanto que en el opuesto, los rectángulos se alternan remetidos y salientes. En éste, los rectángulos forman líneas en zig-zag y en diagonal, y producen, dentro de su bidimensionalidad, un movimiento mesurado, continuo, infinito.

En el día, la obra se vincula con el color azul del cielo, de tal manera que la penetra y la define. El azul es el más profundo, el más inmaterial, el más frío de los colores. El azul intenso recuerda la vida pura y exacta.

En la base de los paños de mosaico, se observan, cifra sagrada, cinco perforaciones en forma de $T$ invertida: es el signo $I k$ de los mayas, el germen de vida eterna, el viento divino que silenciosamente se desliza por la noche. El color blanco es la totalidad y la síntesis de lo distinto, y en esta combinación cromática blanco-azul se simboliza la tierra sublimada. $\mathrm{El}$ mosaico y los huecos en forma de $\mathrm{T}$, son también recuerdos vivificados de signos antiguos. 
El volumen de la obra se compone de formas geométricas simples unidas para formar muros y vanos. Estos últimos son dos enormes aberturas: un círculo en la parte posterior, y un medio círculo que se abre, hacia el frente. De hecho la composición de la obra se rige por estos espacios circulares que traspasan el volumen. El círculo es símbolo universal de perfección y eternidad; el movimiento circular es inmutable, sin principio ni fin ni variaciones; por ello significa también el tiempo, el tiempo como sucesión continua e invariable. Es a la vez símbolo del mundo espiritual, invisible y trascendente del cielo cósmico en su rela ción con la tierra. El círculo es igualmente manifestada protección.

Por encima del círculo, hay otro vano, es una elipse que recuerda un ojo; es la comprensión. La mitad del volumen, un prisma rectangular al cual intersecan los círculos, lleva, en su parte alta, un medio círculo que se abre hacia arriba; un cilindro descansa en su centro.

El carácter simbólico de la obra se refuerza en el interior. El acceso y la planta baja, ricos en texturas, se encuentran poco iluminados, como corresponde al área de iniciación; aquí las cubiertas son convexas y se recubren por troncos naturales, Entre estas cubiertas cuyos muros curvos corresponden a los círculos exteriores, se localiza la escalera dispuesta en tramos divergentes y que dan acceso, por medio de angosto pasaje, a un piso en la parte más alta. La escalera es símbolo clásico de ascensión hacia el conocimiento, la sabiduría y la transfiguración. El piso alto, amplio y luminoso, revela el acceso a la luz divina, al alumbramiento espiritual.

Agustín Hernández creó, con artesanos, técnicos y diseñadores, un monumento que integra con formas, espacios, texturas y colores, una obra total, inseparable y perfectamente armónica en su aspecto material y en su sentido espiritual. La forma hace concreto al símbolo, y éste es la esencia de la estructura visual.

El "Centro de Meditación" recuerda la perfecta unidad de una catedral gótica o de un templo maya; cada elemento que lo constituye se explica y fundamenta, nada en él es accesorio o trivial. Pero si este "Centro" se arraiga en viejos símbolos universales, la manera de combinarlos en armonía es, sorprendentemente, nueva.

No es un edificio, no es una escultura, es una obra de arte que cumple con su destino estético, simbólico y social. 
DOI: http://dx.doi.org/10.22201/iie.18703062e.1986.55.1263 


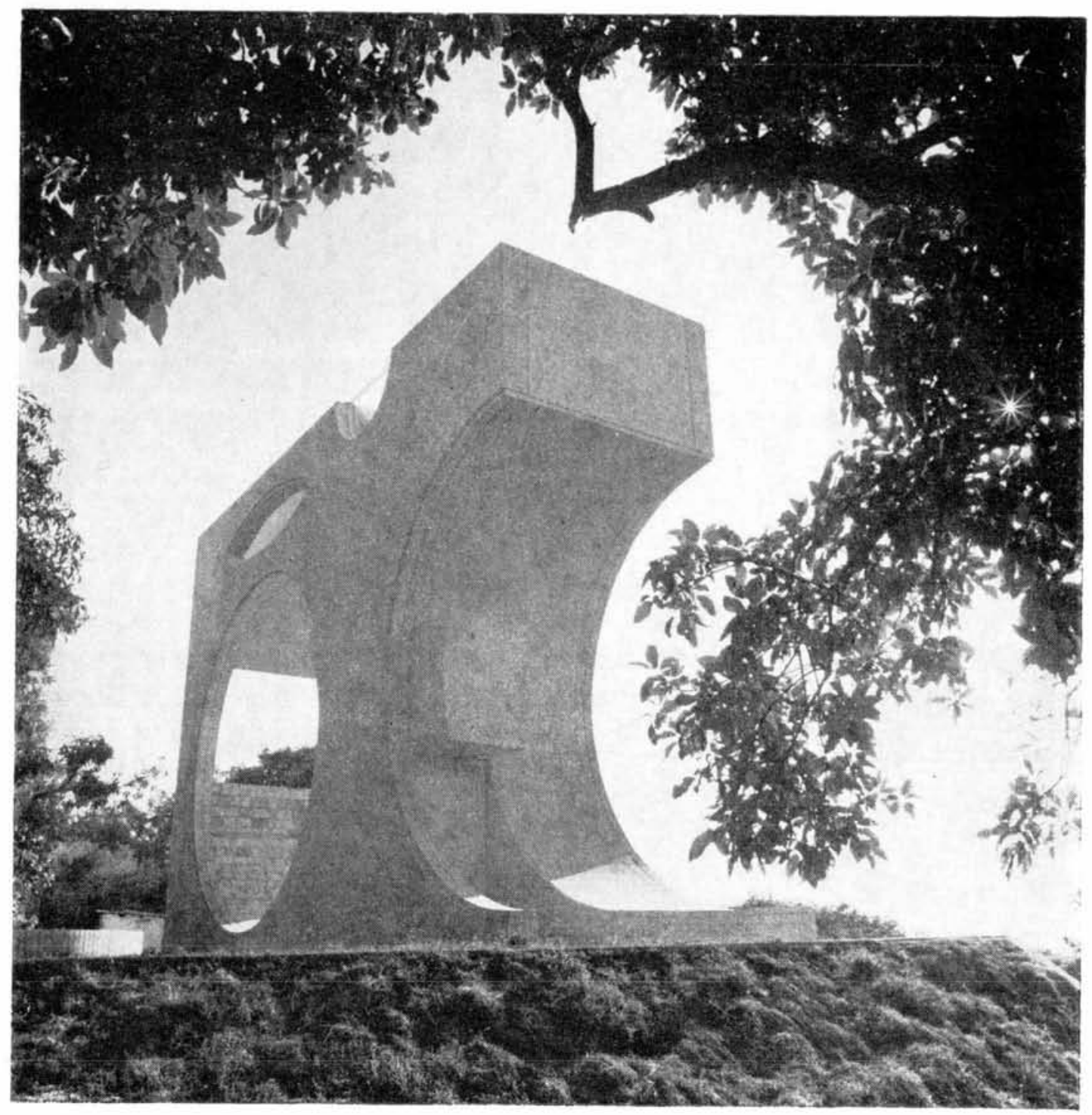

Figura 1. Centro de Meditación, Cuemavaca, Morelos. Vista exterior. 


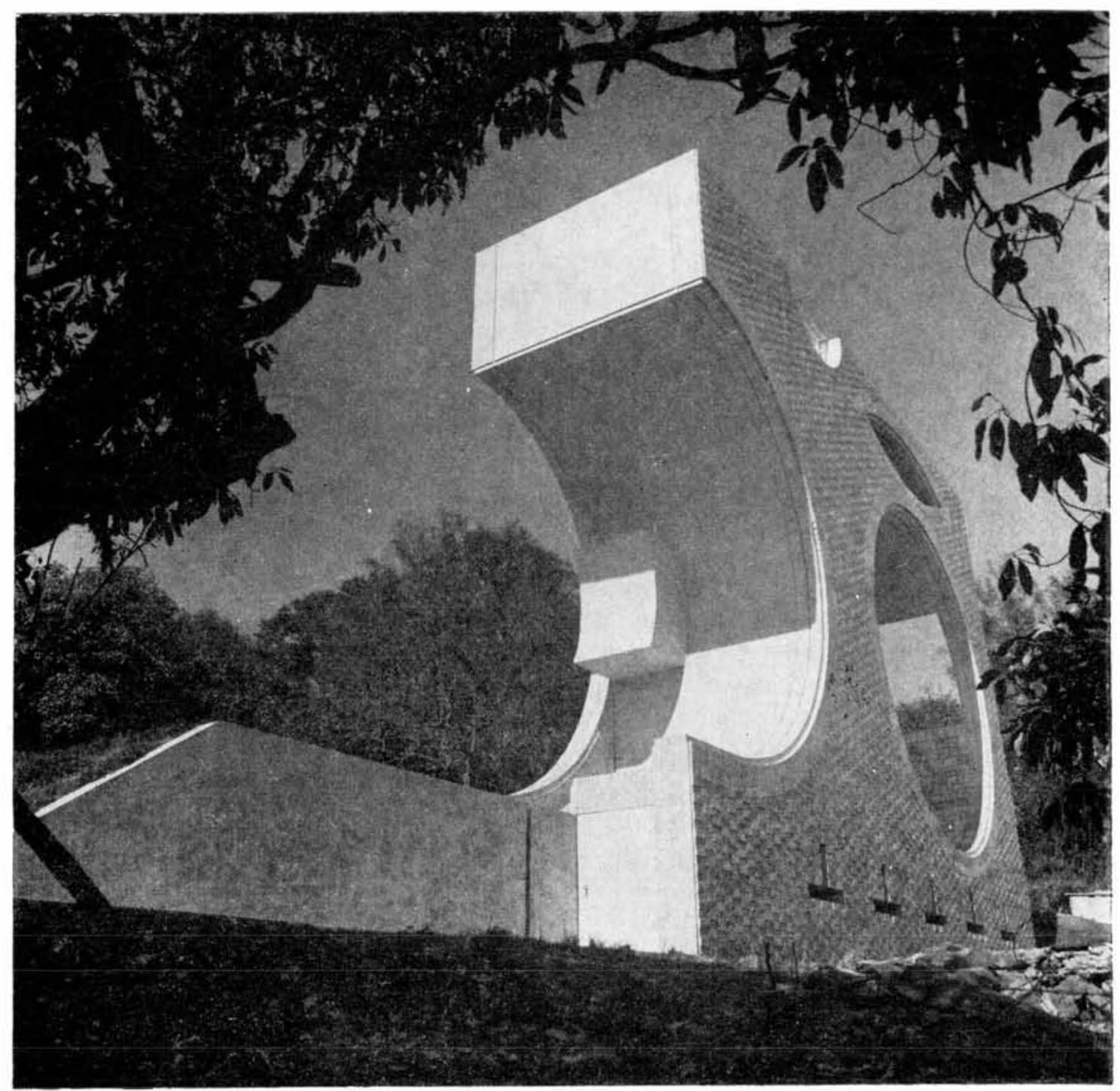

Figura 2. Centro de Meditación, Cuernavaca. Morelos. Vista exterior. 
DOI: http://dx.doi.org/10.22201/iie.18703062e.1986.55.1263

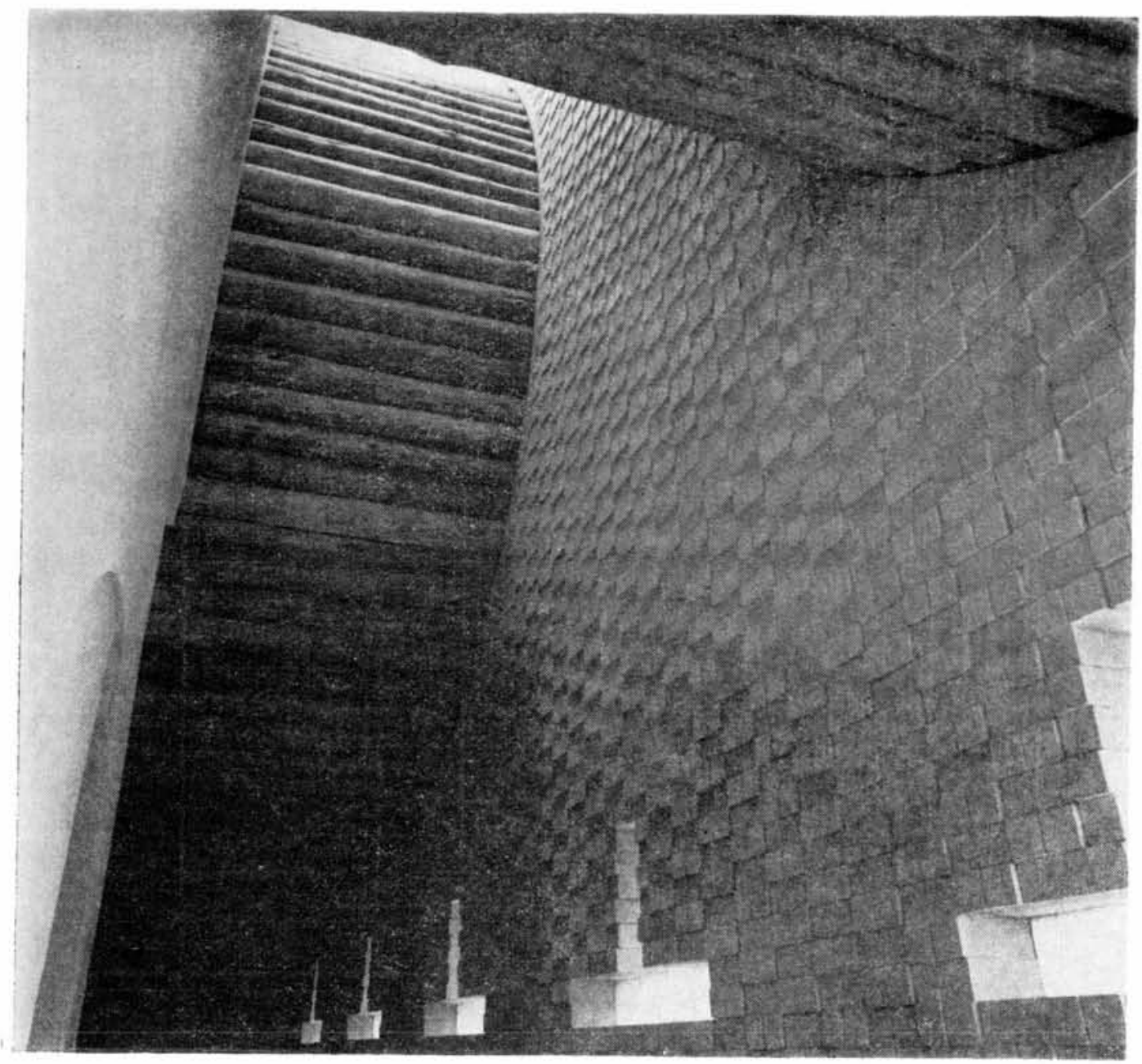

Figura S. Centro de Meditación, Cuemavaca, Morelos, Vista interior. 


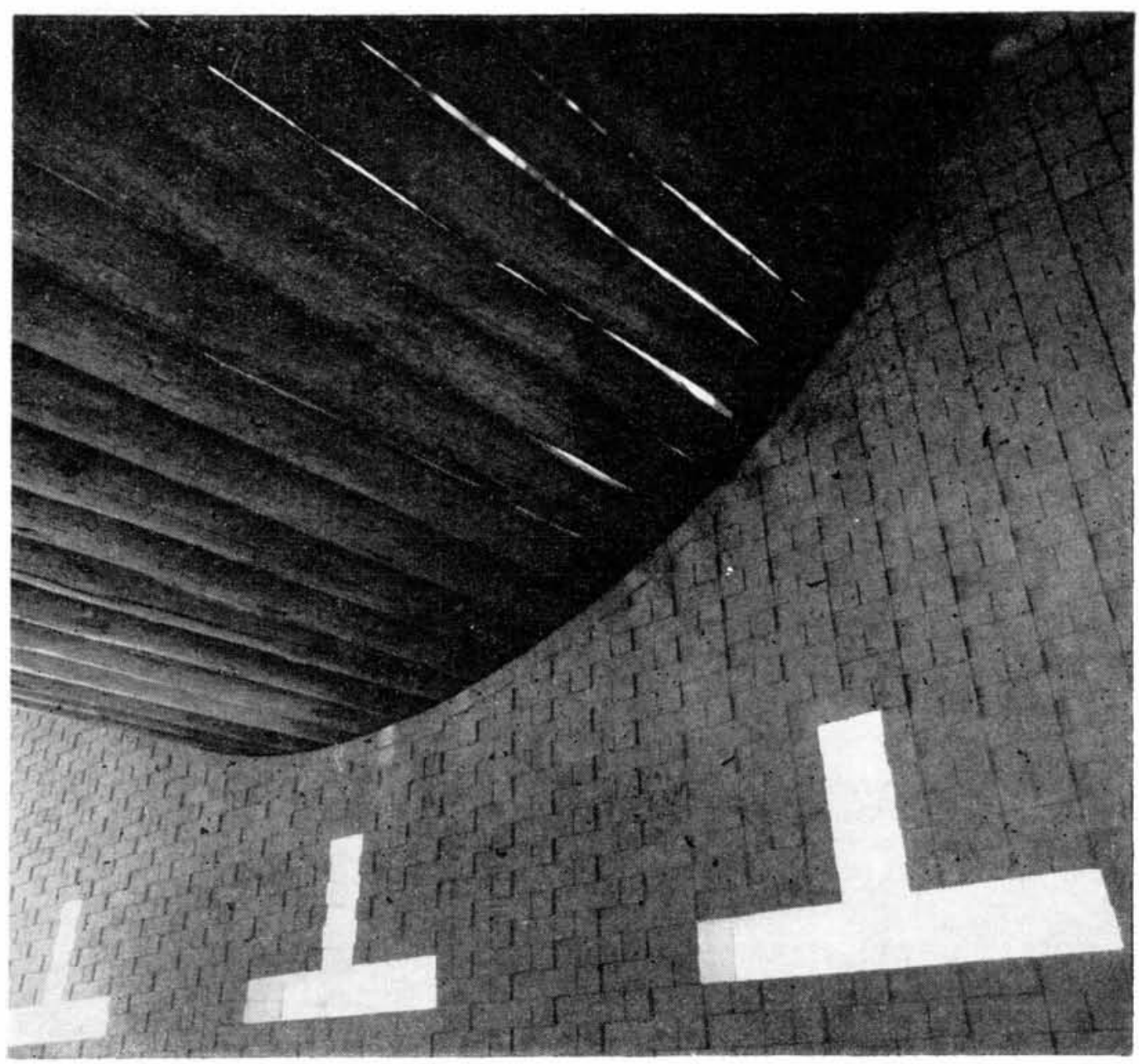

Figura 4. Centro de Meditación, Cuernaraca, Morelos. Vista interior. 